\title{
CIRCULAÇÃO IRREGULAR DE JOGADORES BRASILEIROS NO MERCADO INTERNACIONAL ${ }^{1}$
}

\section{IRREGULAR CIRCULATION OF BRAZILIAN PLAYERS IN THE INTERNATIONAL MARKET}

\author{
Luiz Carlos Ribeiro*
}

\section{RESUMO}

Análise das transações irregulares de jogadores de futebol no mercado internacional, com destaque para a circulação de brasileiros em Portugal. A hipótese aventada é que a grande circulação de jogadores brasileiros no mercado internacional precisa ser compreendida na lógica da globalização, em especial no contexto da flexibilização neoliberal das barreiras comerciais, financeiras e de fluxo migratório.

Palavras-chaves: Futebol, globalização, mercado internacional, migrações.

\begin{abstract}
Analysis of the irregular transactions of soccer players in the international market, with emphasis on the circulation of Brazilians in Portugal. The hypothesis is that the great circulation of Brazilian players in the international market needs to be understood in the logic of globalization, especially in the context of the neoliberal flexibilization of trade, financial and migratory flow barriers.
\end{abstract}

Keywords: Football, globalization, international market, migrations.

${ }^{1}$ Projeto de pesquisa em andamento, com financiamento parcial do CNPq (Chamada Universal MCTI/CNPq 01/2016) e do PIBIC/CNPq/UFPR.

"Professor adjunto IV da UFPR. É pós-doutor pela EHESS-École des Hautes Études en Sciences Sociales (Paris/França) e pelo Instituto de Ciências Sociais, da Universidade de Lisboa. Coordena o Grupo de Estudos "Futebol e Sociedade" (PGHIS/UFPR). 


\section{INTRODUÇÃO}

O objeto do presente artigo é o estudo do processo de constituição do que estamos denominando de circulação irregular de jogadores brasileiros de futebol no mercado internacional.

Portanto, o recorte temático proposto não é a da circulação de jogadores profissionais que saem do Brasil com contratos que cumprem as legalidades formais, mas fundamentalmente, explorar a fronteira pouco visível de um mercado compreendido por uma massa de indivíduos que se aventuram em esquemas irregulares e ilegais, na perspectiva de iniciar uma carreira de jogador de futebol no mercado internacional

Apesar de ser um assunto banalizado na mídia, analisar essa temática da circulação irregular de jogadores exige entendê-lo como um fenômeno polimórfico. Uma heterogeneidade que tem como principal característica a forma obscura como se apresenta na sociedade. E talvez, por conta disso, seja ainda assunto pouco estudado e/ou apenas tangenciado nos trabalhos acadêmicos.

A complexidade do assunto começa já na tentativa de definir uma linha de distinção entre o que seria uma transação regular ou irregular de jogadores futebol. Os casos recentes da transferência do jogador Neymar Júnior do Santos Futebol Clube para o Fútbol Club Barcelona, ou dos envolvimentos de Leonel Messi (Barcelona) e Cristiano Ronaldo (Real Madrid Club de Fútbol) com o fisco espanhol, revelam a falta de transparência como se desenvolvem os negócios no campo futebolístico. Até porque esses casos envolvem jogadores altamente profissionais, clubes tradicionais e contratações supostamente regulares. A nebulosidade das transações financeiras desses atletas borra com frequência a fronteira entre o legal e o ilegal no campo futebolístico.

O nosso ponto de partida, portanto, é tensionar a relação regular/irregular. Ao mesmo tempo em que é notória a existência de instituições solidamente constituídas e regras internacionais claras sobre o sistema de transferência de jogadores e as diversas atividades financeiras do setor, tanto no direito esportivo quanto no direito comum, é preciso reconhecer a convivência desse sistema legal com práticas fraudulentas.

Assim como, tanto no contexto nacional quanto mundial, são pouco visíveis os limites distintivos entre futebol amador - associado à ideia de menor grau de controle -, e futebol profissional - regido por regras oficiais.

Essa dificuldade de distinguir o futebol amador do profissional, nos traz à memória antigas discussões sobre o profissionalismo marrom, dos anos 1930/40.

A explicação para essa situação é que, tanto no campo esportivo quanto no direito e no mercado financeiro comuns, os instrumentos de controle dos processos de transação e circulação de jogadores se apresentam intencionalmente frágeis.

Inscrito como um mercado de incertezas, tanto para o jogador e seus familiares, quanto para agentes, clubes e investidores, a hipótese que levantamos é de que a elevada insegurança do investimento justifica o risco de práticas irregulares e ilegais.

Configura-se uma fragilidade instalada no interior das instituições reguladoras e no sistema, de tal modo que regramento e desregramento convivem num mesmo ambiente.

Como não há garantias de eficácia, o que predomina é a anomia do risco, em que a transgressão é parte do sucesso do negócio. Ignora-se que o elo mais frágil da corrente é o jovem atleta, como bem observa estudo desenvolvido na França

Trata-se de tráfico de menores que apresenta numerosos riscos para todas as crianças, uma vez que o objetivo visado pelos caçadores de talento é vendê-las o mais rápido possível, como mercadorias, de maneira a obter lucros significativos. Contudo, no caso desses jovens menores não se tornarem rentáveis, os empresários e mesmo os clubes não hesitam de jogá-los na rua, sem dinheiro, sem alojamento e sem visto de permanência. (BAKADIABABU, 2001:32)

A incerteza do negócio, para todos os envolvidos, leva a rede a produzir mecanismos de fugas às regras. Regras que se apresentam frouxas exatamente para facilitar os subterfúgios. No dizer de Raffaelle Paoli, referindo-se aos jovens amadores que se aventuram nesse mercado incerto, esses indivíduos não podem ser tratados como "migrantes qualificados" - supostamente por se tratar de uma mão-de-obra diferenciada do trabalhador comum - mas sim de "migrantes a se qualificar". (POLI, 2004) E, no limite, uma qualificação que para a grande maioria nunca se realiza.

Ou seja, a situação de irregularidade, ou de ilegalidade, é de difícil comprovação, na medida em que 
os diversos agentes envolvidos, de forma mais ou menos direta, têm interesse em envolver essas transações num véu pouco transparente. Ocultar as transações do controle público é a melhor forma de garantir o sucesso do negócio.

\section{A GUISA DE EXEMPLO, UM CASO SINGULAR}

Exemplos que demonstram a relação promíscua entre o legal e ilegal, entre o atleta amador que inicia a sua carreira e o formalmente instalado no mercado profissional não faltam. Vamos apenas citar um exemplo que, pela sua atualidade e pela importância institucional dos agentes envolvidos, dá bem uma ideia da rede complexa a que nos referimos.

No dia $1^{\circ}$ de junho de 2017 o Club Atlético de Madrid foi, em decisão final, punido pelo Tribunal de Arbitragem Desportivo (CAS, em inglês), da FIFA (Fédération Internationale de Football Association), acusado de contratar jogadores menores de idade.

A sanção foi inicialmente imposta em janeiro de 1917 pelo Comitê Desportivo da FIFA, em consequência das irregularidades do time espanhol ao contratar jogadores menores de idade para atuar no clube. A investigação concluiu que o time violou as regras estipuladas nos regulamentos da FIFA para a contratação de jogadores menores de idade, em 65 dos 183 casos investigados.

Pesquisando sobre alguns dos agentes envolvidos nesse caso, localizamos o magnata Wang Jianlin, da empresa Wanda, que é também proprietário de $20 \%$ das cotas do Atlético de Madrid.

Em parceria com Atlético de Madrid, o empresário coordena o Projeto Wanda, que tem a proposta de "mobilizar 1 milhão de jovens chineses praticando futebol": "Se o projeto for mantido pelos próximos dez anos, tem potencial para produzir jovens promessas capazes de jogar em ligas europeias, e, inclusive, pela seleção chinesa", previu Wang em pronunciamento à imprensa. (UOL ESPORTES, 2017) Por conta desse projeto, desde 2011 o empresário vem financiando a estadia de 180 jovens chineses em centros de treinamento da Espanha.

Simultâneo, a Wanda se tornou, a partir de março de 2017, numa das principais patrocinadoras da FIFA, substituindo antigos patrocinadores - Emirates e Sony - que se retiraram após os escândalos de corrupção na entidade, em 2014 (O GLOBO, 2016). Ainda em janeiro de 2017, a empresa organizou a Copa da China, um torneio Fifa criado e financiado pela Wanda, que teve a participação de China, Islândia, Croácia e Chile.

Entre centenas de casos que podemos citar, este envolvendo a empresa global Wanda, o Club Atlético de Madrid e a FIFA exemplifica a complexidade que é distinguir o que é regular e o que é irregular no mercado internacional de jogadores de futebol.

Reduzir a explicação do mercado ilegal de jogadores de futebol como uma atividade marginal de agentes inescrupulosos é ingenuidade e só reproduz a falta de transparência existente.

\section{O POSICIONAMENTO DA FIFA}

Na questão específica do tráfico de atletas menores - uma das críticas mais contundentes do poder público - as instituições dirigentes do futebol posicionam-se, no mínimo, de forma ambígua. Apesar de se manifestar contrária à mercantilização de atletas menores de 18 anos, o regulamento da FIFA abre uma condição excepcional: "se os pais do jogador se instalarem no país do novo clube, por razões estranhas ao futebol" (FIFA, 2014:22). Ou seja, ao invés de agir no sentido de coibir as transferências de menores de forma incisiva, legitimam uma das formas mais utilizadas pelo mercado ilegal de jogadores menores, que é usar a contratação dos pais por alguma empresa comercial ligada aos dirigentes do clube ou a agentes envolvidos no negócio, viabilizando desse modo a transferência do atleta menor.

E é desse modo frouxo e descomprometido com a situação do tráfico internacional de jogadores menores que a FIFA se posicionou formalmente em documento recente:

A FIFA só é capaz de regular as atividades promovidas no âmbito do futebol organizado. Questões relacionadas com a "tráfico de crianças", como qualquer outra atividade criminal, é da competência das autoridades nacionais e internacionais (polícia, judiciais ou governamentais). Estas questões estão fora da jurisdição da FIFA, mas congratulamo-nos, naturalmente, muito favoravelmente com qualquer medida que demostram que as autoridades levam a sério e, por meio de nossas disposições relativas à proteção dos menores, contribuímos para, na esfera de competência da FIFA, buscar soluções a este grande problema. (FIFA, 2016) 
Ora, é óbvio que não cabe à FIFA o papel de agente policial no combate ao crime de tráfico de menores. Mas, considerando que o foco propulsor dessa prática, no âmbito esportivo, se encontra "no futebol organizado", e sobretudo nos grandes e ricos clubes europeus, espera-se da entidade máxima do esporte mais do que congratular-se com as autoridades pelas suas iniciativas. E mais, se a prática existe, como a própria FIFA reconhece, inclusive quando pune seus filiados, é porque o problema se encontra exatamente no âmago do futebol organizado. A atividade criminosa só existe porque os grandes clubes, as federações nacionais e internacionais atuam na sua proliferação. O que a FIFA faz é simplesmente negar a sua responsabilidade com essa conduta, tornando-se, portanto, conivente. Na prática, ao se negar a enfrentar efetivamente o tráfico de menores no meio futebolístico, a entidade atua como legitimadora da irregularidade, mesmo que indiretamente. Portanto, reafirmo, qualquer tentativa de afirmar que o tráfico internacional de jogadores menores se encontra nas mãos de indivíduos outsiders ao sistema, é falso. A situação é apresentada dessa maneira exatamente para não enfrentar o problema onde ele realmente se encontra, ou seja, no âmbito do futebol organizado e profissional.

A publicação da FIFA do quadro de transferência internacional de jogadores menores, nos últimos anos, serve para constatar como esse nicho específico do mercado internacional de jogadores vem crescendo.

Quadro 1 - Transferência internacional de jogadores menores.

\begin{tabular}{|l|l|l|l|l|l|}
\hline \multicolumn{1}{|c|}{ Ano } & 2011 & 2012 & 2013 & 2014 & 2015 \\
\hline Demanda total & 1500 & 1747 & 1845 & 2189 & 2716 \\
\hline Aceitos & 1343 & 1527 & 1637 & 1929 & 2323 \\
\hline Rejeitados & 157 & 220 & 208 & 260 & 393 \\
\hline
\end{tabular}

Fonte: FIFA, 2016.

Nesse período, tanto a demanda quanto as transferências legais de jogadores menores de 18 anos aceitas tiveram um crescimento médio de $80 \%$, fato que pode ser interpretado como ampliação tanto de mercado legal, facilitado pela flexibilização de relações econômicas e financeiras, quanto do ilegal, que se aproveita do afrouxamento institucional.

Uma vez que a legislação esportiva o permite, é plausível entendermos que esses dados se referem a transferências regulares de jogadores menores. Porém, apesar de revelar uma tendência preocupante, os dados não dão conta do universo do mercado irregular/ilegal existente que existe como uma franja invisível.

De todo modo, é explícita a crescente demanda por jogadores mais jovens. A tendência progressiva por atletas menores atende a uma lógica de mercado, pois em geral esses são mais baratos. Não se encontram ainda valorizados em seus clubes, sendo que a maioria deles joga em clubes menores e mesmo amadores em seu país.

Trata-se de uma prática que, pela forma predatória com se efetiva, desorganiza a vida pessoal (social, educacional e psíquica) dos jovens atletas pois, para a maioria deles, o resultado desse processo é o abandono, tornando-se ainda mais socialmente vulneráveis.

Assim como também se configura uma propensão que compromete a formação de novos atletas nos países importadores, desequilibrando o processo formativo dos jovens. Ou seja, para esses países, comprar no exterior jovens atletas sai mais em conta do que formar os locais que, como cidadãos nacionais possuem toda uma carga de direitos sociais e trabalhistas que os estrangeiros, pela sua vulnerabilidade, não exigem. Essa conduta, como reconhece a própria FIFA prejudica sobretudo os jovens originários de condições de países de reduzido controle social, como ocorre nas regiões da América latina e África:

Os jovens jogadores podem estar vulneráveis (exploração e abuso), pois se encontram em um país estrangeiro, sem medidas de controle adequadas. Se a transferência internacional pode, em alguns casos, beneficiar a carreira de atleta jovem, na maiorias das vezes essas transferências de modo algum os beneficia. (FIFA, 2016)

Porém, apesar da tentativa da entidade de mostrar preocupação com o controle desse mercado irregular, é óbvio que a grande massa do mercado ilegal de jogadores menores encontra-se fora dos quadros estatísticos oficiais.

Como afirmamos acima, a opção pelo termo "irregular", primeiro, não significa afirmar, pura e simplesmente, uma distinção clara em relação ao mercado "regular". Segundo, a opção pelo termo "irregular" e não "ilegal", foi sugerida por diversos agentes, tanto do meio esportivo quanto da sociedade em Portugal, 
como órgãos públicos e ONG's que atuam em defesa dos direitos sociais dos migrantes comuns.

Direitos humanitários esses que, apesar de absolutamente justos, borram ainda mais a distinção entre o que deve ser criminalizado e o que é o direito social de um sujeito precarizado que, de modo geral, é a situação do migrante irregular.

Apesar de difícil a distinção, esse dilema não se aplica aos sujeitos que, aproveitando-se da ingenuidade e/ou vulnerabilidade do migrante, o utiliza para ter ganhos pessoais. No limite, é o caso dos que atuam na viabilização do contrabando ou tráfico de crianças, em geral socialmente vulneráveis, que ocorre no meio futebolístico.

\section{TRANSFERÊNCIAS INTERNACIONAIS DE JOGADORES DE FUTEBOL}

Em publicação realizada em maio de 2017, L'Observatoire du football, do CIES apresentou um importante estudo sobre jogadores de futebol que atuam fora de seu país de origem. O termo, em francês, utilizado para definir esses profissionais é expatriés. Essa expresão, expatriado, em português tem conotação forte de degredado, deportado, desterrado, exilado ou proscrito. Como em francês o termo é mais amplo e em geral define o sujeito que atua por circunstâncias as mais diversas, fora do seu país, preferimos utilizar os termos estrangeiros ou exportados, no sentido de diferenciá-lo do jogador que atua em seu próprio país.

Nesse estudo, L'Observatoire du football analisou a situação de 2.120 clubes, num total de 12.051 jogadores, em todas as confederações e ligas profissionais de futebol no mundo. (CIES, 2017)

Entre os países que mais exportam jogadores, de longe o Brasil é o principal, com o registro de 1.202 atletas, liderança que se mantém desde os anos 1980/90, quando se intensificou a diáspora de brasileiros pelo mundo, um dos principais subprodutos da globalização do mercado. Com base no documento do CIES, apresento abaixo um recorte dos principais países exportadores de jogadores de futebol:
Quadro 2 - Principais países exportadores - maio 2017

\begin{tabular}{|l|l|}
\hline Brasil & 1.202 \\
\hline França & 781 \\
\hline Argentina & 753 \\
\hline Sérvia & 460 \\
\hline Inglaterra & 451 \\
\hline Espanha & 362 \\
\hline Alemanha & 335 \\
\hline Croácia & 323 \\
\hline Nigéria & 292 \\
\hline Uruguai & 288 \\
\hline Colômbia & 284 \\
\hline Portugal & 240 \\
\hline Gana & 236 \\
\hline Holanda & 232 \\
\hline Bélgica & 216 \\
\hline
\end{tabular}

Fonte: CIES, 2017.

A análise da presença significativa, nesta lista, de países tradicionalmente importadores de jogadores, é pouco desenvolvida no artigo. Apenas para a França e Inglaterra há algum destaque. No caso francês, afirma o estudo:

$\mathrm{Na}$ maioria dos casos, trata-se de jogadores de origem argelina que cresceu na França e que regressaram ao país de seus pais para prosseguir a sua carreira profissional de jogador. (CIES, 2017)

Ou seja, trata-se de uma situação muito singular. Por mais que esses jogadores tenham a cidadania francesa, o que se está exportando são indivíduos que vivenciam situações com oportunidades econômicas, sociais e esportiva inferiores à dos sujeitos tradicionais e estabelecidos. Faz uma diferença fundamental, na França, ser nascido em famílias brancas e católicas tradicionais, de ser imigrante ou descendente, e habitar em bairros pobres com população majoritariamente árabe. Revela-se aqui uma complexidade étnico-social na França que demandaria uma longa análise, a qual não teríamos como desenvolver nesse artigo.

Como também é peculiar o caso da Inglaterra, reconhecido o maior importador de jogadores de futebol da era da globalização. Segundo o L'Observatoire $d u$ football, é seguinte a explicação à proeminência inglesa também nas exportações:

A presença da Inglaterra entre as cinco principais associações exportadoras de jogadores de futebol, 
está fortemente relacionado ao grande número de expatriados ingleses para outras nações britânicas, incluindo País de Gales (143 jogadores) e Escócia (114). Mais de metade dos ingleses que jogam no exterior tiveram seus desenvolvimento nos clubes desses países. (CIES, 2017)

Em outras palavras, mais da metade dos exportados ingleses dirigem-se a países da própria comunidade britânica. ${ }^{2}$ Trata-se muito mais de uma circulação interna à comunidade, do que propriamente um processo de migração entre culturas social e economicamente diferentes.

Um estudo mais profundo desse quadro, tanto na França quanto na Inglaterra, demandaria uma análise das origens sociais desses migrantes. Se no caso do Brasil existe já um paradigma indicativo de que os jogadores em sua maioria são originários das camadas sociais mais pobres, resta conhecer esse fenômeno da migração em países ricos e de menor desigualdade social.

Os casos da Espanha e Alemanha, identicamente apontados como países exportadores, mereciam também um estudo à parte, pois certamente os números apresentados ocultam especificidades quanto a origem desses jogadores, que saem para jogar no exterior. Assim como o caso de Portugal que, apesar de não ser tão relevante em termos numéricos, demanda igualmente um estudo mais específico. Portugal pode ser comparado ao caso francês - presença de jogadores originários ou descendentes de ex-colônias. Não descartaria a possibilidade de, entre esses exportados lusos, encontrarmos brasileiros naturalisados. Teríamos aqui outro exemplo de situação de repatriação, como na França.

Se esses casos europeus chamam a atenção pelo paradoxo, países da América Latina, da Africa ou do leste europeu são vistos hoje como exemplos claros e "naturais" de exportadores de atletas.

\footnotetext{
${ }^{2}$ À guisa de esclarecimentos, nos jogos da FIFA (Copa do Mundo e Eurocopa) cada membro da comunidade britânica (Inglaterra, Escócia, País de Gales e Irlanda do Norte) se apresenta com seleção própria. O mesmo não ocorre nas Olimpíadas quando, fiéis à tradição olímpica, a seleção britânica de futebol é formada basicamente por atleta amadores. Nessa competição a Grã-Bretanha sempre teve dificuldade de montar uma seleção, deixando de participar em diversas competições. Sua participação em 2012 (Olimpíada realizada em Londres) foi polêmica, inclusive com atletas não ingleses da seleção de futebol, tanto do masculino quanto feminino, se recusando a cantar o tradicional hino britânico, God Save the Queen (Deus salve a Rainha, em inglês). Pelos mesmos motivos, na Olimpíada de 2016, no Brasil, a Grã-Bretanha não se fez representar no futebol, nem no masculino nem no feminino.
}

De todo modo, o estudo é uma demonstração da complexidade do processo de circulação internacional de jogadores de futebol. A fragilização dos mecanismos tradicionais de controle do mercado internacional - tanto comercial, financeiro quanto de fluxo de pessoas - transformou o campo futebolístico numa rede hibrida, borrando a leitura binária tradicional de sul/pobre-norte/rico.

\section{A SITUAÇÃO ESPECÍFICA DE BRASILEIROS EM PORTUGAL}

Verificando especificamente a transferência de jogadores brasileiros para o mercado português, o diagnóstico de que Portugal é o principal receptor de jogadores de futebol brasileiros, desde os anos 1980/90, se confirma com o nosso levantamento. Segundo dados do CIES, em maio de 2017 Portugal acumulava $18 \%$ do total de registros oficiais de brasileiros que atuam no exterior. (CIES, 2017)

Com base nos dados extraídos dos boletins da CBF-Confederação Brasileira de Futebol, entre os anos 2003-2008 Portugal já absorvia uma média anual de $18 \%$ das transferências de atletas brasileiros para o exterior. Por mais que esses dados sejam pouco confiáveis, na medida em que compila apenas as transferências legais, a informação é relevante, ainda mais se comparada com o fato de as cinco maiores e mais ricas ligas do futebol mundial (big-5: Espanha, Itália, Alemanha, Inglaterra e França) terem, juntas, atraído apenas $14 \%$ dos brasileiros. Assim, mesmo que o fluxo de jogadores brasileiros para o exterior tenha diminuído em termos absolutos - o grande pico teria ocorrido entre os anos 1990-2010 - Portugal continua sendo o principal mercado a que se destinam os brasileiros.

Constata-se, portanto, que a inconsistência dos registros de jogadores brasileiros transferidos para o exterior coincide com a dificuldade em se obter informações precisas sobre brasileiros residentes em Portugal, exatamente pela existência de uma franja invisível de ilegais, ou que se utilizam do país como uma "escala temporária", conforme situação já diagnosticada em relação a emigração brasileira para a Europa.

Efectivamente, Portugal vai cada vez mais aparecer como um nexo importante de toda a emigração brasileira para a Europa, como uma espécie de platafor- 
ma de lançamento. Cada vez mais redes vão interligando o Brasil, Portugal e um terceiro país, dentro da União Europeia, sendo muito normal que os migrantes circulem por esses três lugares. Portugal está a transformar-se numa espécie de porto seguro para os Brasileiros na Europa. (MALHEIROS, 2007:198)

Segundo o sociólogo português Carlos Nolasco, entre 1990/1 e 2010/11 - período de sua pesquisa - entre os clubes profissionais de Portugal a "esmagadora maioria dos jogadores estrangeiros" é composta de brasileiros. No período esportivo de 2010/11, 60\% dos atletas dos clubes da Primeira Divisão do futebol português era de brasileiros. (NOLASCO, 2012)

Dados levantados por nós no mês de julho de 2017 mostram que essa situação se modificou, mais ainda é significativa a presença de brasileiros. De acordo com nosso levantamento, existia nessa data 457 jogadores brasileiros registrados em Portugal, entre profissionais e amadores, como demonstra o quadro abaixo.

Quadro 3 - Jogadores atuantes no futebol português. Por nacionalidade, julho de 2017.

\begin{tabular}{|l|l|l|l|l|l|l|l|}
\hline & Clubes & \multicolumn{2}{|l|}{ Portugueses } & \multicolumn{2}{|l|}{ Brasileiros } & \multicolumn{2}{l|}{ Outros } \\
\hline I Liga & 18 & 133 & $33 \%$ & 121 & $30 \%$ & 154 & $38 \%$ \\
\hline II Liga & 22 & 436 & $55 \%$ & 124 & $15 \%$ & 236 & $30 \%$ \\
\hline $\begin{array}{l}\text { Liga } \\
\text { amadora }\end{array}$ & 70 & 1521 & $72 \%$ & 212 & $10 \%$ & 373 & $18 \%$ \\
\hline
\end{tabular}

Fonte: Quadro organizado pelo autor a partir de fontes especializadas.

O número proporcionalmente menor de brasileiros - assim como o de outras nacionalidades - nas divisões amadoras, pode ser indício de ocultamento de um fluxo de atletas sem registro, que é o que caracteriza a circulação irregular de jogadores estrangeiros em Portugal. Pela maior exposição junto a torcedores, mídias e autoridades, os clubes profissionais são os que menos se arriscam ter em seus quadros atletas em condições irregulares, sejam eles menores ou não. Oposta é a situação dos clubes amadores, até por que são esses que fazem o papel de intermediários, selecionando atletas que seguirão carreira profissional, seja em Portugal ou repatriados a outros países europeus.

Apesar das denúncias constantes na imprensa a respeito da existência de um número significativo de jogadores em situação irregular em Portugal, em especial brasileiros, pouco é feito no sentido de se coibir essa prática. Existe sobre o assunto um silêncio, tanto das autoridades esportivas quanto públicas. A única exceção tem sido a do Sindicato dos Jogadores Profissionais de Futebol (SJPF), em especial na figura de seu presidente, Joaquim Evangelista. Em 2012 Evangelista fazia denúncias claras da existência de jogadores irregulares em Portugal. Vejamos alguns trechos de entrevista concedida na ocasião:

O que é grave é que há grupos identificados a promover isso, agentes que trazem oito, nove, dez jogadores, colocam-nos num local em condições desumanas e há clubes que são coniventes com essa realidade. O negócio, vamos ser claros, é a realização de uma transferência. (...)

Estou a falar das ligas profissionais também, os jogadores quando são transferidos são normalmente para clubes de patamares superiores, há pessoas nesse nível que pactuam com isto, fazem parte da cadeia. (...)

Diria que, por cada caso que é identificado, haverá 100 ou 200 que não o são. (EVANGELISTA, 2015)

Em síntese, afirma Evangelista, "há uma rede organizada de tráfico de jogadores de futebol em Portugal". Foi de iniciativa do SJPF (Sindicato dos Jogadores Profissionais de Futebol), em 2015, a assinatura de um protocolo efetivado entre o sindicato, o Serviço de Estrangeiros e Fronteiras (SEF), a Federação Portuguesa de Futebol (FPF) e a Liga Portugal que visava coibir a presença de jogadores irregulares em Portugal. É pouco provável que FPF e a Liga tenham interesse efetivo em controlar seus filiados, uma vez que são esses que financeira e politicamente sustentam as entidades. Salvo por eventuais disputas internas, não há divergências substantivas entre dirigentes de clubes e das entidades diretivas. É assim com a CBF, no Brasil, e com a FIFA em nível mundial.

Como há, portanto, um forte esquema de dissimulação de responsáveis, há enorme enorme dificuldade para se comprovar a existência do tráfico ou de situação irregular de jogadores.

Grosso modo o esquema começa a funcionar desde o país de origem do atleta, quando um agente ou mesmo um clube de formação seleciona um talento, cantata a família e faz a proposta de jogar no exterior. Conforme o interesse do agenciador a família adianta recursos para a documentação, como 
passaporte e passagem, ou o próprio agente providencia, até mesmo fazendo adiantamentos como roupas e tênis ou mesmo material escolar para os irmãos. Os escolhidos são levados sozinhos ou com os país. Não é incomum, no caso de menores, o pai ou a mãe migrar junto, facilitando assim a entrada do menor no país de destino. Em geral o pai/mãe vêm já com promessa de emprego em alguma empresa dos agentes envolvidos - geralmente comércio, restaurantes ou construção civil - legitimando assim a viagem do menor. Viajam com visto de turismo e permanecem algum tempo nos clubes amadores. Evidentemente sem nenhum contrato, ou apenas um contrato fictício, sem valor legal. Quando o período de experiência termina a grande maioria é devolvida para as suas famílias, quando menores, ou simplesmente são deixados à sorte, em alojamentos precários sem documento legal de permanência, sem dinheiro sequer para se alimentar. Muitos acabam permanecendo como ilegais por que funciona em paralelo um complexo esquema de trabalho ilegal que vai desde o emprego informal no comércio ou na construção civil, atividades de camelô até o envolvimento com o mercado de droga e prostituição. Esses raramente apresentam queixa às poucas pessoas que conhecem no novo país - seu "agente", os dirigentes do clube -, primeiro por que há sempre a esperança de serem chamados para um contrato com algum clube, segundo por que sabem da sua situação irregular e temem a polícia. Essa é uma descrição comum na imprensa e em alguns poucos depoimentos de jovens que passaram por essa experiência, como observamos nesse relato:

A sua inexperiência não o deixa alcançar a gravidade da situação em que está inserido. Ilegal, sem documentos, vende Cd's ilegais e provavelmente nunca vai seguir a carreira de jogador de futebol. (FIGURAS E NEGÓCIOS, 2015)

Como a questão de emigração é um sério problema em Portugal - aliás como em toda a Europa - o sistema de controle de fronteiras é bastante severo. $\mathrm{O}$ SEF publica a cada ano um relatório detalhado das migrações. Há ao mesmo tempo, uma série de publicações, seja de iniciativa dos órgãos estatais, seja do meio universitário, abordando os problemas relativos às migrações, onde questões relacionadas à formação do tráfico organizado, ao tráfico de órgãos e de crianças, do tráfico de mulheres e de violência sexual são abordados, mas não há nenhum relato oficial que trate de um fenômeno por todos reconhecidos e do qual a imprensa noticia quase todo dia: o tráfico e/ou a situação irregular de jogadores de futebol, seja de origem brasileira (a maioria) ou de outras nacionalidades, como os africanos ou os de origem do leste europeu.

Os próprios atletas (e familiares) envolvidos acabam silenciando, seja por desconhecerem seus direitos, seja por temer o controle policial, ou por temer a repressão de dirigentes de clubes e agentes envolvidos na transferência ilegal. Como também há o fator da humilhação de um projeto pessoal fracassado. Um projeto que em geral teve o envolvimento da família, amigos e até mesmo vizinhos, e que havia criado a expectativa de sucesso. Afinal, isso é o prometido aos jovens amadores: viajar para o exterior, jogar em um grande clube europeu e, claro, ganhar muito dinheiro. Destaquemos que há nesse processo mais um elemento complicador, que é a ideia do consentimento da vítima, seja ele de maior de idade, ou de menor, no caso a ciência dos pais.

Leiamos o relato de alguns casos, conforme localizados na imprensa portuguesa:

Davi é brasileiro e pagou 1600 Euros para jogar em Portugal. Queria uma oportunidade para mostrar as suas técnicas. Pouco tempo depois de ter chegado percebeu em que esquema estava envolvido. Contou ao Jornal o que passou: "a princípio, foi a alimentação. Para o pequeno-almoço, o cara comprava seis caixas de leite para 15 jogadores. Isso não existe. Pão, ele compra seis sacos para durar de sexta a sexta, mas entre refeições e treinos, em menos de nada, já as provisões tinham acabado. O café da manhã dura dois dias, café da tarde não-tem-nada, refere, acentuando cada palavra. Não vou dizer que eles passam fome a cru. Mas se passares aqui... ele não come macarrão nem come arroz com feijão $\mathrm{e}$ atum todo o dia na casa dele (...) Uma vez por semana, um dos jogadores deixa as instalações para voltar umas horas mais tarde com alguns sacos de compras. É sempre assim que funciona a reposição da despensa".

Caio é brasileiro um foi um dos casos que ajudou a despoletar a investigação sobre as redes de recrutamento de jogadores ilegais em Portugal. Prometeram-lhe contrato de trabalho como jogador de futebol. Na altura em que viajou a família teve que pagar as despesas no valor aproximado de 3.000€. Entre essas despesas estava o pagamento do certificado internacional de jogador. Os responsáveis 
pela sua contratação, um português e um brasileiro colocaram-no à experiência no Naval $1^{\circ}$ de Maio. Quatro meses depois de ter chegado ainda não tinha tido assinado nenhum contrato. E o negócio ficou sem efeito, tendo sido expulso do clube ficando sem apoio de ninguém.

Em 2007 - Anderson foi contratado pelo jogador do FC Porto e, na altura foi um dos casos mais conhecidos no que diz respeito à contratação de estrangeiros ilegais. Nunca foi provado que estivesse em situação ilegal mas, várias vezes foram publicadas notícias de que a legalização do atleta teria sido conseguida através de um contrato de trabalho fictício apresentado pela mãe, do ainda menor Anderson. Outros jogadores estrangeiros do clube estiveram sob suspeita. Ninguém foi constituído. (FIGURAS E NEGÓCIOS, 2015)

No caso do atleta Caio, o presidente do clube respondeu de forma esquiva, afirmando que o atleta havia se apresentado voluntariamente no clube e que desconhecia a situação irregular dele em Portugal. Assim como no caso de Anderson, em se que concluiu por se responsabilizar poucas pessoas. Na maioria dos casos nunca aparecem contratos, nunca aparecem os responsáveis, os atletas na maioria das vezes não são legalizados e acabam na rua sozinhos e sem solução.

Segundo notícias veiculadas pelo SEF, em fevereiro de 2015 mais de 100 clubes foram inspecionados pelo órgão, numa operação de controle da imigração ilegal. Cerca de 500 jogadores estrangeiros foram identificados pelas autoridades, 200 dos quais tinham algum tipo de problema a resolver com as autoridades. Ao final, a polícia de fronteiras apresentou um balanço da situação:

O Serviço de Estrangeiros e Fronteiras (SEF), detetou situações de irregularidade na presença e na atividade em território nacional de jogadores estrangeiros de futebol das camadas jovens em alguns clubes. A operação de fiscalização foi realizada ontem, dia 25 de Março, e incidiu em 16 clubes, a maior parte da primeira liga. Esta ação surgiu na sequência de outras que o SEF tem realizado e nas quais detetou um número significativo de atletas em situação de permanência e de atividade irregular no território nacional.

O Serviço de Estrangeiros e Fronteiras (SEF), detetou situações de irregularidade na presença e na atividade em território nacional de jogadores estrangeiros de futebol das camadas jovens em alguns clubes.
Foram identificados 103 atletas estrangeiros, 16 dos quais foram notificados para comparência nas instalações do SEF, a fim de aferir com rigor a sua situação no país. (PORTUGAL, 2015)

Como se pode perceber o termo utilizado pelo serviço de fronteiras é "irregularidade. A opção por esse termo não é apenas uma questão de semântica, mas um posicionamento político relevante.

Uma das motivações deve-se à contemporização das autoridades públicas em relação ao envolvimento clubístico. Ou seja, os clubes de futebol, pela paixão e envolvimento, acabam protegidos ou pelo menos negligenciados pelas autoridades. Resulta que muitos dirigentes são inicialmente advertidos das irregularidades, permitindo que se livrem do problema ou, quando interessa, regularizem a situação do atleta no clube, o que é menos comum. Evidente que essa é uma hipótese difícil de ser comprovada, mas a frouxidão como são tratadas as irregularidades no campo esportivo destoa do controle existente em outras práticas de tráfico de pessoas, como é caso por exemplo da exploração sexual de mulheres ou mesmo o tráfico laboral.

Outra motivação é de cunho político-humanitário, ou seja, a leitura que entende serem essas crianças ou jovens vítimas de um sistema mercantil e que criminaliza-los só aumentaria o seu sofrimento e vulnerabilidade. A dificuldade em responsabilizar e punir os agentes que se beneficiam do negócio da transferência irregular é que uma ação desse tipo atingiria igualmente o jogador. Afinal, no limite ele é parte da fraude. Gera-se, portanto, uma tendência humanitária de proteção à vítima, preferindo, a concessão de um prazo de 90 dias para que a situação seja regularizada no clube. Período suficiente para que o problema oficialmente deixe de existir, seja pela legalização do atleta - situação mais rara -, seja pelo simples descarte e abandono do jogador.

\section{UM FENÔMENO GLOBAL E COMPLEXO}

A análise do fenômeno da circulação irregular de jogadores brasileiros de futebol para o exterior e, mais especificamente para Portugal, não pode ficar restrito ao campo esportivo. Sem dúvida o elemento de atração desses jovens - menores ou maiores de idade - é um fator específico do meio futebolístico, 
que é o sonho de se tornar um jogador profissional de fama internacional. Mas essa simples constatação revela a fragilidade social e cultural brasileira. A imensa maioria desses jovens que se iludem com essa perspectiva o fazem por que se encontram cultural e socialmente fragilizados.

É evidente que há todo um esquema mafioso para iludir esses jovens e seus familiares. Mas é um esquema que só progride por que encontra as condições para se fortalecer. Não é por acaso que as principais fontes de fornecimento desse tipo de oferta de jogadores se localizem na América Latina e África. A base desse comércio ilegal ou irregular é a falta de oportunidade dos jovens nessas regiões. São as camadas mais pobres que ofertam esse tipo de mão de obra disponível e barata. No limite a situação desses supostos jogadores de futebol não é diversa dos trabalhadores informais da construção civil, no Brasil ou em Portugal.

Portanto, ao mesmo tempo em que o fenômeno da diáspora de atletas tem como centro o campo esportivo, ele não pode ser compreendido descolado do contexto social mais amplo.

A constatação do movimento de intensa mercantilização do campo esportivo e de espetacularização do jogador de futebol coincidir com o movimento de globalização, a partir dos anos 1980, não é mero acaso.

O grande fluxo de jogadores brasileiros para o mercado internacional só pode ser compreendido no processo da globalização da economia mundial. Assim como a espetacularização que o futebol experienciou, tendo se transformado em uma indústria multinacional do consumo de massa, momento em que alguns jogadores se transformam em verdadeiras estrelas pop e a atividade torna-se uma empresa global de ganhos excepcionais.

O movimento da globalização promoveu a flexibilização de barreiras, tanto comerciais e financeiras, quanto possibilitou a intensa circulação de pessoas. Foi essa internacionalização descontrolada do capital que afrouxou as relações trabalhistas nas sociedades economicamente fortes, liberando as barreiras à entrada da mão-de-obra barata imigrante, tornando-se esta uma das mais sensíveis e visíveis faces da globalização. É nesse contexto que localizamos o grande fluxo de brasileiros em direção ao estrangeiro. Se os Estados Unidos foi o principal destino da migração laboral dos brasileiros, Portugal ganhou destaque também pela migração de jogadores de futebol.

Os fatores do êxodo de brasileiros ao estrangeiro são em geral associados à sucessão de crises econômicas e políticas, experimentadas pelo Brasil entre o final dos anos 80 e o início dos 90, como as altas taxas de desemprego, inflação elevada, insegurança pública, insegurança política (por exemplo, o impeachment de Collor, em 1992). É relevante destacar como a resposta do mercado à crise do final dos $70 \mathrm{e}$ início dos 80 , no Brasil, repercutiu na reestruturação do sistema produtivo e no que ficou conhecido como “desemprego estrutural". (PEIXOTO, 2007)

Nesse período, comportamento diverso ocorreu em Portugal. Ao ingressar na União Europeia, em 1986 e aderir à União Econômica e Monetária, em 1999, o país recebeu um grande aporte de investimentos, o que permitiu conhecer uma rápida modernização de sua economia, dando sinais claros do aumento da demanda por mão-de-obra estrangeira, como nos descreve Malheiros:

Do ponto de vista do país de recepção, Portugal fez uma trajectória de emigração para imigração, entre os anos 80 e 90 . A entrada na CEE em 1986, que injectou muitos milhões de euros em Portugal, contribuindo para a dinâmica da economia portuguesa, entre meados dos anos 80 e o início do século XXI, apoiada em sectores como as obras públicas, o comércio - a beneficiar de uma forte expansão do consumo ampliada pela generalização dos mecanismos de acesso ao crédito - e os serviços financeiros, deu um contributo relevante para este processo. Efectivamente, a modernização das infraestruturas nacionais (redes de transportes, equipamentos de nível regional e nacional...), associada à transição para uma economia de serviços e a algumas mudanças sociais tais como o crescimento limitado, mas importante, dos níveis de qualificação dos jovens, criaram as condições necessárias para atrair um grande número de imigrantes. (MALHEIROS, 2017:7)

Outros aspectos que nos ajudam a compreender a intensidade do movimento de brasileiros em direção a Portugal são as facilidades globais de mobilidade (como a redução no preço das passagens aéreas, por exemplo), os novos meios de comunicação que tornaram mais rápido e eficaz os relacionamentos à distância e, claro, as flexibilizações em geral das fronteiras. 
Além desses fatores, considere-se também as peculiares das proximidades culturais, políticas, e sobretudo linguística, entre Brasil e Portugal.

Grosso modo, os estudos realizados apontam para a existência de duas vagas migratórias de brasileiros em direção a Portugal. Uma primeira, entre os anos 1970 e meados de 1980, "composta por uma larga parcela de imigrantes com níveis de instrução elevados e que se inseriram em segmentos mais qualificados do mercado de trabalho português. (IDEM, p. 14) Entre as quais destacam-se os profissionais de marketing e decoração de interiores e a polêmica onda de dentistas brasileiros.

E, de forma mais visível, uma "segunda vaga" de emigração de brasileiros, efetivada entre o final dos anos 1980 e início de 2000. Essa é uma fase em que os brasileiros não apenas tornaram-se a maior comunidade de estrangeiros residentes em Portugal, como colaboraram na intensificação das redes ilegais de imigração, como nos observam esses autores:

Numa segunda fase - a "segunda vaga" (...) -, posterior ao final dos anos 90 , predominaram as entradas de trabalhadores destinados aos segmentos menos qualificados e mais precários do mercado de trabalho. Esta imigração recente foi superior, em valor absoluto, aos fluxos anteriores e perdeu, em larga medida, a lógica de contracorrente. Os canais de migração também mudaram: de uma lógica de canais informais de migração e suporte, passou-se para um peso significativo das redes de contrabando e tráfico de migrantes. Em suma, a imigração brasileira veio a incorporar, no seu seio, a dualidade social e profissional que a imigração, como um todo, já apresentava. (PEIXOTO, 2010:109)

Pela sua densidade na cultura local - desde 2008 os brasileiros representam cerca de $25 \%$ da população estrangeira em Portugal - a comunidade brasileira passou a ser destaque nos estudos e a sofrer um maior controle por parte dos poderes públicos. Essa relevância numérica transformou a comunidade de brasileiros em Portugal a mais tensionada, em geral relacionada a questões como ilegalidade de residência, posição no mundo do trabalho, deslizando em diversos momentos para a construção de preconceitos étnicos e de gênero, e mesmo manifestações de xenofobia, como constata leitura realizada pelo antropólogo Igor Machado:
Toda a imagem sobre o Brasil, seja por parte de Brasileiros ou de Portugueses, é marcada pela ideia de um corpo brasileiro, de uma corporalidade específica, mais sensual, mais flexível, mais doce, mais malandra, mais feliz. Ideias que são sempre exemplificadas pela ginga do jogador de futebol, pelo "jogo de cintura" das prostitutas brasileiras. A construção de um corpo, de uma forma de estar e agir, movimentar, olhar, pegar, é fundamental na construção de uma identidade ou de uma cultura. (MACHADO, 2009:177)

Com base nos dados de 2007 - momento de pico da segunda vaga,$- 87 \%$ dos brasileiros residentes em Portugal encontravam-se em setores que demandam mão-de-obra pouco qualificada e muito próximos da informalidade, tais como comércio e serviços (43\%), restaurantes e hotelaria (39\%) e construção civil (15\%). (COSTA, 2009:134)

É no interior dessa massa de indivíduos que se encontra o jogador brasileiro de futebol - informal ou amador -, em Portugal. A situação não é diferente da vivida por esses jovens no Brasil, nas transferências dos clubes amadores, dos centros de formação, para os clubes profissionais. A diferença talvez seja apenas que, no Brasil, a facilidade de voltar para casa seja mais prática do que se estar no exterior.

Mas o que se constata é que cada vez mais o mercado de trabalho dos jogadores de futebol desfaz as fronteiras nacionais. O número de jogadores estrangeiros nas equipes só se faz aumentar e, sensível por uma lógica de preços da mercadoria, a idade exigida desses migrantes tem sido crescentemente mais baixa. $\mathrm{O}$ mercado internacional cada vez mais se interessa por jogadores menores de idade, mesmo que eles sejam um risco de investimento. Mais baratos do que os jogadores já formados, pela oferta abundante são mão-de-obra descartáveis.

A abundância de oferta dessa mão de obra nos mercados da América Latina, África, leste europeu e mais recente da Ásia, compensa o risco. A voracidade pelo lucro, insisto, não é apenas de agentes inescrupulosos e marginalizados. O que procuramos demonstrar é que a prática do tráfico, ou se preferirmos do mercado irregular de jogadores de futebol, se encontra institucionalizado no sistema futebolístico. Os grandes clubes, nacionais ou internacionais, compõem uma rede complexa de branqueamento do profissionalismo marrom, utilizando-se para isso de um esquema de 
transferências de jogadores menores de idade, na sua maioria originários da América Latina, África e Ásia, sendo o Brasil um dos grandes fornecedores. Resta às autoridades públicas atuarem como reguladoras de um mercado cuja força de crescimento se encontra exatamente no afrouxamento do controle institucional.

\section{REFERÊNCIAS}

BAKADIABABU, Evariste Tshimanga. Le commerce et la traite des footballeurs africains et sud-américains en Europe. Editions L'Harmattan, 2001.

COSTA, Paula. Imigração em Portugal: Tendências recentes. Os imigrantes guineenses, ucranianos e brasileiros no mercado de trabalho português. In: Cadernos Curso de Doutoramento em Geografia. Porto: FLUP-Faculdade de Letras, Universidade do Porto, 2009.

EVANGELISTA, Joaquim. "Há grupos que deixam jogadores em condições desumanas". Mais Futebol, $12 \mathrm{fev} .2015$. Disponível em: <http://www.maisfutebol. iol.pt/imigracao-ilegal-sef-clubes-liga-ii-liga-agentesdesportivos-fiscalizacao-condicoes-desumanas/54dcb9140c f2f64faad2c6ad.html>. Acesso em: 19 fev. 2015

FIFA. Protection des mineurs. FAQ. Set. 2016. Disponível em: $<$ http://resources.fifa.com/mm/document/affederation/ administration/02/83/14/23/faq_protectionofminors august2016_fr_french.pdf $>$. Acesso em: 09 nov. .2017b.

FIGURAS E NEGÓCIOS. África e Brasil são baús de talentos. Negócio de jogadores ilegais movimenta milhões. 29 ago. 2015. Disponível em: <http://www.figurasenegocios.co.ao/content.aspx?africaebrasilsaobausdetalentosnego ciodejogadoresilegaismovimentamilhoes $>$. Acesso em: 23 maio 2016.

MACHADO, Igor J. de Renó. Cárcere público. Processos de exotização entre brasileiros no Porto. Lisboa: ICS-UL, 2009.

MALHEIROS, Jorge M. (Org.) Imigração brasileira em Portugal. Lisboa: Alto-Comissariado para a Imigração e Diálogo Cultural, 2007.

NOLASCO, Carlos. Entre a defesa e o ataque, os imigrantes do futebol português. VII Congresso Português de Sociologia. Universidade do Porto, 19-22 jun. 2012.

O GLOBO. Grupo empresarial chinês Wanda é o novo patrocinador da Fifa. 18 mar. 2016. Disponível em: $<$ https://oglobo.globo.com/esportes/grupo-empresarialchines-wanda-o-novo-patrocinador-da-fifa-18910524>.

PEIXOTO, João; IORIO, Juliana. Crise, imigração e mercado de trabalho em Portugal: retorno, regulação ou resistência? Cascais (PT): Fundação Calouste Gulbenkian / Principia, 2010.
PEIXOTO, João. Tráfico, contrabando e imigração irregular. Os novos contornos da imigração brasileira em Portugal. Sociologia, Problemas e Práticas. 2007, n. 53, p. 71-90.

CIES. [POLI, Rafaelle, RAVENEL, Loïc, BESSON, Roger]. Les footballeurs expatriés dans le monde. Rapport mensuel de l'Observatoire du football CIES. ${ }^{\circ} 25$, maio 2017.

POLI, Raffaele. Des migrants à qualifier. Les footballeurs africains dans quatre pays européens. In: La mobilité internationale des compétences. Situations récentes, approches nouvelles. L'Harmattan, 2004. p. 143-164.

PORTUGAL. SEF. Fiscalização a clubes de futebol. Lisboa, 26 mar. 2015. Disponível em: <http://www.sef.pt/portal/v10/ $\mathrm{PT} / \operatorname{aspx} /$ noticias/Noticias_Detalhe.aspx?id_linha $=6780>$. Acesso em: 10 jul. 2015.

UOL Esporte. Magnata do futebol chinês diz que país precisa desenvolver categorias de base. 23 mar. 2017. Disponível em: <https://esporte.uol.com.br/ultimas-noticias/ efe/2017/03/23/magnata-do-futebol-chines-diz-que-paisprecisa-desenvolver-categorias-de-base.htm>. Acesso em: 20 maio 2017. 